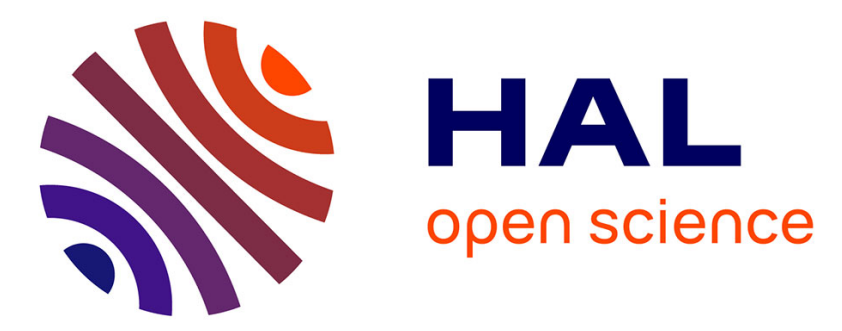

\title{
Efficacy of a visuomotor-based intervention for children with reading and spelling disabilities: a pilot study
}

Smail Layes, Mohamed Salah Chouchani, Robert Lalonde, Mohamed Rebaï

\section{To cite this version:}

Smail Layes, Mohamed Salah Chouchani, Robert Lalonde, Mohamed Rebaï. Efficacy of a visuomotorbased intervention for children with reading and spelling disabilities: a pilot study. British Journal of Special Education, 2019, 46 (3), pp.317-339. 10.1111/1467-8578.12278 . hal-03220039

\section{HAL Id: hal-03220039 \\ https://hal.univ-lorraine.fr/hal-03220039}

Submitted on 6 May 2021

HAL is a multi-disciplinary open access archive for the deposit and dissemination of scientific research documents, whether they are published or not. The documents may come from teaching and research institutions in France or abroad, or from public or private research centers.
L'archive ouverte pluridisciplinaire HAL, est destinée au dépôt et à la diffusion de documents scientifiques de niveau recherche, publiés ou non, émanant des établissements d'enseignement et de recherche français ou étrangers, des laboratoires publics ou privés. 


\title{
Efficacy of a visuo-motor based program for children with reading and spelling
}

$$
\text { disorders - a pilot study }
$$

Smail Layes, Salah Chouchani, Robert Lalonde, Mohamed Rebaï

\begin{abstract}
We predicted that Arabic-speaking dyslexic children with spelling disorder benefit from a visual motor based remediation program for the development of letter knowledge and the improvement of spelling (dictation) as well as word and pseudo-word decoding. It was predicted that the mediation of visual motor training should be effective since the characteristics of Arabic script require such high-level functioning for the development of literacy skills. Twenty native Arabic children from grade 4 with specific learning disorders in reading (dyslexia) and spelling (dysorthographia) took part in this study. Participants were randomly divided in two equally sized groups, an experimental group $(n=10$; mean age $=125.50$ months \pm 3.24$)$ and a control group $(n=10$; mean age $=124.10$ months \pm 3.31$)$. The intervention program focused on the development of visuo-motor representations of letters to strengthen letter-sound associations as a way to acquire the alphabetic principle needed for learning to read and write (sound to letter correspondence). Results revealed that the post intervention measures were better achieved in the experimental group than pre-intervention ones. Findings approve the efficiency of the visuomotor intervention program for the remediation of decoding and spelling disorders.

Keywords: dyslexia, spelling disorder, visual motor intervention, alphabetic principle, letter representation.
\end{abstract}




\section{Introduction}

The term 'specific learning disorders' (SLDs) is used to describe a group of learning difficulties characterized by impaired performance in reading (decoding accuracy, fluency, and comprehension), spelling, written expression, or calculation, despite average or above average intelligence (DSM-5; APA, 2013). In respect to this definition, two learning disorders are taken into account in this study: reading decoding disorder or dyslexia which refers to the inability to perform accurate or fluent word reading (incorrect reading of single words aloud), and spelling disorder of sound to letter correspondence. Spelling requires the ability to differentiate individually heard sounds and mapping those sounds into letters (i.e. alphabetic knowledge, Sayeski, 2011). Difficulties in written expression (e.g. multiple grammatical or punctuation errors, poor expression and organization) represent another aspect of SLDs falling beyond the scope of the present study.

Spelling disorder was labelled "dysorthography" in DSM-4 TR (2002), which refers to a disorder in writing (orthographic skills and phonographic coding), different from dysgraphia as a disorder in hand-writing (graphomotor) skill. In dysorthography, the spelling of words is highly deficient as a direct consequence of the phonological disorder in dyslexic children (Inserm, 2007). In addition, poor performance in spelling is associated with "dysorthographia", referring to a specific learning disability manifested by grammatical errors, arbitrary spelling, and many spelling errors as in the addition of letters and/or syllables, omissions, substitutions, and reversals (Pierangelo \& Giuliani, 2007).

Although the indication of the DSM-5 (APA, 2013) and several findings suggest an association between learning disorders in dyslexia and spelling disorder (Lyon et al., 2003; Egan and Tainturier, 2011), the major focus of most studies has been reading disabilities (Bigozzi, Christian, Pinto, \& Gamannossi, 2016; Schiff \& Levie, 2017). Consequently, most remedial 
research studies have been dedicated to children with reading disability. Nevertheless, children with dyslexia usually have serious problems with spelling as well (e.g. Berningera, Nielsena, Abbotta, Wijsmanb, \& Raskind, 2008), show writing problems at the word level (e.g. Angelelli, Marinelli, \& Zoccolotti, 2010) and were found less accurate in writing from dictation than agecontrolled children (Suárez-Coalla, Villanueva, González-Pumariega \& González-Nosti, 2016). Therefore, young learners with dyslexia often need more effective instruction and strategies for learning to read and spell as they may have difficulties in using sound-letter correspondence rules. This study was designed to examine the efficacy of a remedial program based on visual motor representation of alphabetic letters for the development of decoding and spelling (dictation) in a group of native Arabic reading disabled children with spelling disorder (dysorthography).

Early literacy studies suggest that the alphabetic principle is a fundamental underlying skill for reading and spelling (Eden \& Moats, 2002; Ehri, 2000), promoting an awareness of letter sounds (letter knowledge) in alphabetic languages (Treiman, Tincoff, Rodriguez, Mouzaki, \& Francis, 1998). To learn decoding and spelling accurately, children must master the alphabetic principle and be aware that spoken words consist of sounds linked to letters or letter groups (Moll, Kunze, Neuhoff, Bruder, \& Schulte-Korne, 2014). It is well documented that deficient acquisition of the alphabetic code in children with dyslexia is causally linked to the great difficulty (error rate) in spelling observed in pseudo-words more than regular words, because it requires the use of a sub-lexical strategy. The poor performance with pseudo-words has already been described in dyslexic children of opaque and non-opaque orthographic systems, especially in the first years of writing experience (e.g. Angelelli, Judica, Spinelli, Zoccolotti, \& Luzzatti, 2004; Caravolas \& Volin 2011).

Reading and spelling disorders are highly correlated to impairments in alphabetic knowledge. The phonological deficit theory postulates that children with reading disorders have a specific impairment in the representation, storage, and/or retrieval of speech sounds. In 
dyslexic subjects, these sounds are poorly represented, resulting in inappropriate retrieval of the learned alphabetic system, a poor relation between visual representations of the stored letter and its associated phonology (Brady \& Shankweiler, 1991). Consequently, the acquisition of inconsistent sound-letter mappings in individuals with dyslexia increases their errors in literacy tests (Angelelli et al., 2004; Landerl \& Wimmer). Since letter knowledge acquisition is an important component of children's literacy, it must be considered in any remediation program (Hammill, 2004; Pennington \& Lefly, 2001; Vaessen \& Blomert, 2013), especially in transparent orthographies (Hulme \& Snowling, 2013).

In addition, literacy performances (reading, spelling, and writing,) are commonly related to visuo-motor skills (Goldstand, Koslowe, \& Parush, 2005). Recent reports show that motor skills have significant correlations with reading (Knight \& Rizzuto, 1993) and facilitate children's abilities in reading (Son \& Meisels, 2006). Based on the assumed role of visuo-motor skills in literacy development and the underlying letter representation deficit which impedes alphabetic knowledge acquisition in children with reading and spelling disorders, we predicted that letter recognition may be successfully acquired via visuo-motor training. This should be well applicable to Arabic scripts, because written alphabetic units (letters) change partially their forms according to the position in the word (beginning, middle, and end) and which can be regrouped into clusters of shapes based on their visual similarities (e.g. Abu-Rabia \& Sammour, 2013). In addition, these letters have a similar or even identical basic shape and can be distinguished only on the basis of the existence, location, and number of dots (Azzam, 1989). Children may have an inability to associate letter shapes into sounds, a difficulty in establishing and retrieving soundvisual configuration associations as symbols. Thus, a remedial program based on integrating visuo-motor skills along with letter-sound associations may promote letter representation and therefore increase reading, decoding, and spelling abilities in children with dyslexia and spelling disorders. 
Few studies exist on the contribution of visuo-motor training on forming the alphabet principle and literacy abilities. Hall, Simpson, Guo, and Wang (2015) found five studies concerning letter formation by hand as part of literacy intervention. In Neumann, Hood and Ford (2013), children were asked to write a letter in the air and in a journal with a pencil after teacher demonstration. In the Li \& James (2016) study, preschool children learned novel Greek symbols through either writing, tracing typed symbols, tracing handwritten symbols, visually studying typed symbols, or visually studying handwritten symbols. Results indicated that the groups who studied handwritten forms, either through tracing, viewing, or seeing their own writing, learned the symbols better than those who studied typed letter forms. These results suggest that visual experience with symbols that are highly variable in their forms (through handwriting or tracing) facilitates visual recognition of written symbols. These results were viewed as evidence of the multimodal nature of letter representations learned through matching of visual configurations and movements, where the sensorimotor component is integrated (Longcamp, Anton, Roth, \& Velay., 2005). According to these authors, movements organize perceptions and link this to learning to read, for when alphabetic letters are reproduced by specific hand movements, children can access their perceptual-motor system and recognize the letter through memory.

Vinter and Chartrel (2010) investigated the respective advantages of visual, motor, and visuo-motor training on the performance of 5-year-old children in writing isolated cursive letters. They found that visuo-motor training was the most effective. The efficacy of visual training was clear at the letter quality level, suggesting that such training better contributes to learning the shape of a letter. Likewise, Bara and Bonneton-Botte (2017) assessed the impact of a teacherimplemented visuo-motor intervention program to teach 5-year-old children cursive letter knowledge. The authors compared the impact of a program in which alphabet letter production was explored with the arm and whole body with a typical visual training program on letter knowledge acquisition. The main finding was that letter recognition improved more after the visuo-motor training program than the typical visual training program. Like haptic exploration 
(Gentaz, Bara, Palluel-Germain, Pinet, \& Hillairet de Boisferon, 2009) and handwriting (Labat, Ecalle, \& Magnan, 2010; Longcamp et al., 2005), gross and fine motor exploration of letters has a particularly positive impact on their recognition. And so, this practice may be helpful for children with reading and spelling disorders.

To the best of our knowledge, our study is the first empirical one in Arabic. Some orthographic characteristics in Arabic (e.g. visual similarities between letters) are thought to be a source of errors in reading and spelling (Ibrahim, Eviatar, \& Aharon-Peretz, 2002). This difficulty has been mainly attributed to differences in letter shape determined by placement of the letter within a word and therefore different grapheme configurations share the same phoneme, which may create a difficulty in establishing letter identity. In their classifications of reading and spelling errors among dyslexic Arabic readers compared with normal ones, Aburabia and Taha (2004) observed that visual letter confusion errors are among the most prevalent, either as a result of confusion of letter-shape similarities in reading producing a mismatch between graphemes and phonemes, or as a confusion between similar visual shapes of letters in spelling, hence the lack of the grapheme-phoneme conversion rules. These types of error can be considered a direct result of the uniqueness of written Arabic orthography (Abu-rabia \& Taha, 2004). In the current study, we predicted that dyslexic children with spelling disorders could benefit from a visuo-motor remedial program for the development of letter representation. This advantage should be directly reflected in word and pseudo-word decoding and spelling

(dictation) performances. Similar improvements should occur in visuo-motor tasks (block construction and design copying) as indicators in the development of such skills.

\section{Method}

\section{Participants}

Participants were initially recruited as poor readers $(n=55)$ primarily on teachers' opinions and then based on poor performances for word and pseudo-word reading. After eliminating cases whose profiles did not match with inclusive criteria, twenty children composed 
the group study, diagnosed with dyslexia based in at least $-1.5 \mathrm{SD}$ below the mean scores in word and pseudo-word reading (dysorthographia) based on a criterion-referenced test of sentence dictation. Children did not suffer from any specific learning disability other than reading and spelling, or hearing or visual impairments, and had average scores on Raven Standard Matrices. Participants were equally divided into two groups following a randomized design in which they were assigned to each condition individually, an experimental group $(n=10)$ with a mean age of 125.50 months $(S D=3.24)$ and a control group $(n=10)$ aged 124.10 months $(S D=3.31)$.

All participants were right-handed and had normal hearing without ophthalmological or neurological abnormalities, were native Arabic speakers exposed to Standard Arabic in regular classes and exempt from any other comorbid disability (e.g. oral language disability, ADHD). No differences appeared between the two groups on age and Raven scores (Table1).

\section{Measures}

\section{Pre and post training measures}

Raven test. The Raven Standard Progressive Matrices is a non-verbal test of reasoning ability and general intelligence. We used the shortened form (Bouma et al., 1996) comprising 36 items (Sets A, B, and C) and consisting of a target matrix with one missing part. The children selected from six to eight alternatives to fill the missing patch.

Word and pseudo-word reading tasks. Pseudo-word decoding is a widely used measure to assess children's decoding and orthographic learning skills (Ehri, 2005; de Jong \& Messbauer, 2011). Pseudo-word requires both phonemic segmentation ability and knowledge of grapheme-phoneme correspondence, not allowing for sight reading as a possible strategy (Castles \& Coltheart, 1993). Good, Baker, \& Peyton (2008) suggested that skills necessary for decoding are isolated from the ability to read words by sight during pseudo-word reading, because the reader cannot rely on past experience. Instead, the reader relies on understanding letter-sound relations (i.e. the alphabetic principle) and the rules that govern those relationships and then applies this knowledge for decoding. 
A list of eighty words $(\alpha=.82)$ was given and read aloud (40 frequent words and 40 infrequent words). The words varied in length (di-syllabic and tri-syllabic) and frequency (high and low). In addition, 40 pseudo-words $(\alpha=.90)$ controlled for orthographic length were used (Layes et al., 2014; Layes et al., 2015a, b). Children able to segment and with good knowledge of letter sound correspondences will perform better on pseudo-word decoding tasks than those who do not (Tunmer \& Nesdale, 1985).

Spelling test: Sentence dictation. It consists of dictating ten small sentences of three words each where children were instructed to write down the heard sentence (Elbeheri, 2004). The sentences contain several phonological, orthographical, and grammatical target words from high to low frequency of occurrence (Tops, Callens, \& Brysbaert, 2012; Tops, Callens, Bijn, \& Brysbaert, 2014). The sentence dictation is limited to the spelling of individual words and the use of the morphosyntactic rules at the sentence level full beyond the scope of the present study. Participants were given a standard form to write on. The test administrator read in full each sentence aloud, repeating each word separately in a uniform way as many times as participants requested. Words were presented with a regular interval of $3 \mathrm{sec}$, so that students could produce an immediate response. No additional information was given about punctuation or capitals. The score is the total number of the correct written words without time limit. The reliability of this test was measured by an external validation sample $(n=55)$. The test-retest reliability (correlation coefficient) was $r=.95$ and the internal consistency reliability (alpha coefficient) $\alpha=.94$.

The visual spatial processing assessment (NEPSY-II).

Two subtests of the Neuropsychological Assessment battery NEPSY-II (Korkman, Kirk, \& Kemp, 2007) were used: the Design Copying and the Block Construction subtests:

Design Copying is a pencil-and-paper task that requires the examinee to copy designs of increasing complexity to assess visuo-motor integration. It requires the examinee to construct three-dimensional models from models and pictures to assess visuo-spatial and visuo-motor skills. Design Copying is a subtest within this domain that evaluates a child's ability to copy 
geometric designs of increasing complexity from a response booklet to assess motor and visual perceptual skills (Korkman, Kirk, \& Kemp, 1998). The Design Copying total score had mean internal consistency coefficients above .70 across all age groups in the norming sample. These scores had mean test-retest reliability coefficients below .70 across ages 7 to 10 , but for ages 11 to 12 , both mean test-retest reliability coefficients were .71 .

Block Construction: This subtest is used to assess visuo-spatial and visuo-motor skills, requiring a child to look at two-dimensional drawings and use blocks to copy them and so construct threedimensional representations (Korkman et al., 1998). This task has been extended upward to cover the age range of 3 through 16 years. The Block Construction total score had mean internal consistency coefficients and mean test-retest reliability coefficients above .70 across all age groups in the normal sample. Scaled scores may be obtained for the total process score as well as for the global motor process.

\section{The intervention program: background and content}

Use is made of combining sources of information that contribute to developing phonological representations that underpin word coding in the mental lexicon for children with disabilities (Perfetti \& Sandak, 2000). Visuo-motor representation can be proposed as an additional source of information that can help children with dyslexia to develop awareness of the phonological structure of letters. Letter exploration was combined with letter-sound correspondence in a multisensory-based intervention perspective, and specific instructions were given to the participants for exploring letters. In any task that involves visual and motor systems, manual manipulation may be a particularly effective pathway to object knowledge (James \& Gauthier, 2006; Longcamp et al., 2005; Longcamp, Anton, Roth \& Velay, 2003). Symbols (e.g. letters or digits) are unique object types that are very rarely manipulated manually, except in the specific case of handwriting when symbols are formed feature-by-feature.

Inspired from the "word work" multisensory instructional decoding method (Blachman, Tangel, Ball, Black, \& McGraw, 1999), this intervention program included targeted decoding 
ability by making explicit connections between phonemes and graphemes through the use of manipulative materials that provide tactile and visual phoneme representations. This method provides a concrete medium for the abstract tasks of phoneme manipulations (Campbell, Helf, \& Cooke, 2008) and may thus be particularly beneficial for struggling readers. Simultaneous links are consistently made between visual (letters), motor (gross and fine movements), and auditory (sounds) pathways. Advocates believe that multisensory input, such as letter multiform imitation and reproduction, strengthens visual memory through conscious awareness of mechanisms such as letter form (shapes) and increases the information stored in memory by providing multiple representations (Moats \& Farrell, 2002).

Based on the above-mentioned theoretical background, our program includes the use of manipulative letters, individual moveable letters such as manually formed and shaped letters, cards with letters printed on them. In addition, letters to form words are removed and then replaced to form a new word. The process is repeated to provide multiple opportunities for decoding, and each successive word typically shares one or more letters in common with the previous word to demonstrate relationships between common sounds and spellings. Moreover, specific activities such as drawing big letters on the blackboard, imitation of letter shapes in various substances, tracing letters in the air and forming letters with modelling clay are proposed within an intersensory intervention approach for elementary school children (Lust \& Donica, 2011). Attention was focused to strengthen the relationship between the visual configurations of letters (shapes) and the corresponding sounds via the perceptual motor bridge. During the visual motor intervention, children were permanently stimulated to reproduce and manipulate the visual configurations of the letters and were trained to recognize the target letters and distinguish them from each other.

The exercises of the intervention program were created to be performed individually and collectively. The program content was organised as follows: 
1. Geometric shape imitation was used to develop perception, visual discrimination of forms and the fine motor skills. There was imitation of geometric shapes (circle - square - rectangle triangle - star - crescent, etc) from the blackboard using modelling clay accompanied with letter naming and then recognition of geometric shapes from memory after removing the visual model from the blackboard.

2. Motor execution of geometric shapes was aimed at developing visual perception, motor spatial memory, and visual motor kinetics. There was reproduction of spatial shapes by hand movement and drawing of geometric shapes from memory after oral instructions.

3. Letter form recognition and discrimination: this activity aimed at developing visual attention, perception, and memory. The participants were instructed to sort and group letters by their form similarities, and select letters from a set, to match a visually presented word without correct seriation of the selected letters required beforehand.

4. Learning the letters: A set of 3 or 4 letters (e.g. which includes:

- The reproduction of visually presented letters using modelling clay and hand movements, sticks, circles, and cards.

- After removing the letters from the blackboard, the same activities are performed.

- Writing the letters after oral presentation

- Presentation of examples of words containing the letters.

The association of letter sound (phoneme) is systematically present in these activities.

5. Linking and arranging letters: Association between words with one missing letter was presented along with a selected letter from a set individually scripted on paper.

6. Word formation: letter cards were used to create words corresponding to visually presented images of different objects.

\section{Procedure}


All participants underwent pre-training tests during the first week of the study, followed by 13 intervention sessions over the course of 6 weeks (two per week, each one approximately $40 \mathrm{~min}$ ), and intervention testing. All procedures were performed in a small private room located in the school setting.

\section{Data Analyses}

SPSS version 22 was used for data analysis. Baseline inter-group comparisons were performed with the t-test for independent samples. As there might be post-intervention effects in the development of word and pseudo-word decoding, spelling, and visuo-motor abilities among the experimental group, MANCOVA with pre-training measurements entered as the covariates was used for between-group comparisons of all post-training measurements. The paired t-test was also used to compare the pre- and post-intervention measurements within the experimental group. Effect size is computed by Cohen's d for the magnitude of the training effect.

\section{Results}

\section{Baseline Assessment}

Due to the small sample size, the assumption of the normality of the distribution of the dependent variable (in the experimental group) for the pre-intervention measure of reading was checked with Shapiro-Wilk ( $\operatorname{statistic}=.94)$, indicating a normal distribution $(\mathrm{p}>.05)$ with a skewness of $0.46(\mathrm{SE}=.68)$ and a kurtosis of $-0.68(\mathrm{SE}=1.33)$. As kurtosis is near 0 , a normal distribution is assumed and parametric tests were applied. With regard to inclusion criteria, comparisons at baseline assessment between intervention and control groups are presented in Table (1), including age levels and Raven scores as well as word and pseudo-word reading, sentence dictation, and visuo-spatial measures.

\section{Insert table 1}

\section{The intervention effects}


To examine whether visuo-motor based intervention improves word and pseudo-word reading in the experimental group, and whether this improvement affects spelling, a one-way multivariate analysis of covariance (MANCOVA) controlling for pre-training measures was conducted to assess the main effect of the group variable (experimental/control) on multiple continuous dependent variables simultaneously (word and pseudo-word decoding, spelling, design copying, and block construction). Statistics provided from Box's M-test of equality of covariance indicated that homogeneity of covariance was met $(\mathrm{F}=1.25, p=.22)$. The omnibus effect for "group" was significant (Pillai's Trace $\left.=.90, \mathrm{~F}_{(5.90)}=16.09, p<.001\right), \eta^{2}=.899$ ).

Follow-up univariate analyses (ANOVAs) show significant differences on the group factor for pseudo-words $\left[\mathrm{F}(1.13)=4.86, \mathrm{p}<.05\right.$, partial $\left.\eta^{2}=.27\right]$, Dictation $[\mathrm{F}(1.13)=57.52, \mathrm{p}$ $<.001$, partial $\left.\eta^{2}=.81\right]$, Design Copying $\left[F(1,13)=11.15, \mathrm{p}<.01\right.$, partial $\left.\eta^{2}=.46\right]$, and Cube Construction $\left[\mathrm{F}(1.13)=40.27, \mathrm{p}<.001\right.$, partial $\left.\eta^{2}=.75\right]$. However, word reading was not different $[\mathrm{F}(1.13)=.42, \mathrm{p}>.05]$.

To examine further the potential impact of the intervention program, paired t-test was performed comparing pre and post intervention measures for the experimental group. Results show significant differences in the post intervention scores for pseudo-word decoding in pre $(M=.80$, $\mathrm{SD}=1.03)$ and post intervention $(\mathrm{M}=2.10, \mathrm{SD}=.87), \mathrm{t}(9)=4.33, \mathrm{p}<.01)$; for sentence dictation in pre $(M=2.70, S D=1.56)$ and post intervention $(M=8.20, S D=2.30), t(9)=13.70$, $\mathrm{p}<.001)$; for Design Copying in pre $(\mathrm{M}=10.90, \mathrm{SD}=3.28)$ and post intervention $(\mathrm{M}=15.80$, $\mathrm{SD}=3.22), \mathrm{t}(9)=6.39, \mathrm{p}<.001)$, and for Block construction in pre $(\mathrm{M}=5.00, \mathrm{SD}=1.94)$ and post intervention $(\mathrm{M}=10.60, \mathrm{SD}=2.87), \mathrm{t}(9)=12.38, \mathrm{p}<.001)$. However, for word reading the difference between pre $(M=17.50, S D=7.38)$ and post intervention $(M=19.10, S D=7.20)$ measurements the $t$-test value only approached significance $(\mathrm{t}(9)=1.98, \mathrm{p}=.07)$. 
This study was designed to examine the impact of a visuo-motor based intervention program on the acquisition of word and pseudo-word decoding and spelling abilities in children with reading and spelling disorders. The main findings were that the experimental group achieved better in post-intervention measures of these literacy abilities. This pattern of results was replicated in the visuo-motor tasks (block construction and design copying). Word reading only approached significance $(p=.07)$. In contrast, the control group receiving no intervention program remained stable across pre- and post-intervention measures.

The results are viewed as a positive impact of the visual-motor based program on word and pseudo-word decoding via the development of letter recognition (Bellocchi, Muneaux, Huau, Lévêque, Jover, \& Ducrot , 2017). The contribution of hand movements on letter recognition and reading acquisition was outlined in previous studies with young children (Bara, Gentaz, Colé, \& Sprenger-Charolles, 2004; Bara, Gentaz, \& Colé, 2007; Gentaz, Colé, \& Bara, 2003), indicating that benefits could be obtained (Bara \& Gentaz, 2011). Weiser and Mathes (2011) examined the impact of phoneme-grapheme manipulation through word work activities on reading and spelling performance for at-risk elementary students with learning disability in reading. Results showed that instruction in encoding increased students' knowledge of the alphabetic principle, development of phonemic awareness, and growth of reading and spelling skills. Similar findings were reported in Bara et al. (2004; 2007), showing that haptic exploration of letters was superior to visual exploration for rate of improvement in kindergarten children's letter recognition, letter handwriting, and pseudo-word decoding. Bara and Bonneton-Botte (2017) also found that visuo-motor training based on gross exploration of letters had a particularly positive impact on their recognition, since such movements match letter shapes as with handwriting, leading to an efficient promotion of the alphabet for typical young children.

During the implementation of the remedial program, exploring letters involved both visual perception and motor interaction processes. As a result, visual representations of letters seemed to be linked to motor representations, resulting in a visuo-motor system that underlies 
letter processing (Giese \& Rizzolatti, 2015; James, 2010; James \& Engelhardt, 2012; Kersey \& James, 2013). This creates a multimodal representation of letters (Longcamp et al., 2005), linking phonology, perception, and motor patterns (Longcamp, Boucard, Gilhodes, Anton, Roth, Nazarian, \& Velay, 2008).

Furthermore, these findings are supported by functional neuroimaging studies which revealed that experience with letters of the alphabet activates pre-motor areas implicated in writing, raising the possibility that letter production contributes to letter recognition even in skilled readers (e.g., James \& Gauthier, 2006; Longcamp, et al., 2003, Longcamp, et al., 2005; Longcamp, Tanskanen, \& Hari, 2006; Longcamp, Richards, Velay, \& Berninger, 2016). Indeed, there is evidence that both visual and motor regions respond during letter perception, in that early letter learning is typically supported through visual-motor practice, such as handwriting or tracing. This suggests direct links in the brain between motor systems and visual perception that interact during handwriting. James and Gauthier (2006) showed that the set of regions activated during letter perception is very similar to the set activated during letter writing. Similarly, both visual and motor regions begin to increase their response when presented with trained letterforms when compared with other untrained stimuli, such as shapes, in preliterate children after very brief experiences with letters (James, 2010; Kersey \& James, 2013). This change in response only occurs after children learn letters through visuo-motor practice.

At the end of the our intervention program when letters are presented in their isolated (individual) form (e.g. كـ ، ش، ر), participants seemed able to apply the more general knowledge in word and pseudo-word decoding and spelling where the target letter is connected to the word (e.g. the letter [ح] in [حليب]). This finding do not support the claim that there are different abstract letter identity units corresponding to different forms of the same letter in Arabic, and that abstract letter identities might be common to a given letter but with indication of the form they appeared in (Friedmann \& Haddad-Hanna, 2012). Letter identity is assumed to be represented in an abstract, modality-independent format in which neither letter-shape nor font are specified 
(Dufor \& Rapp, 2013). It is worth noting that the body of the letter in Arabic generally does not change whatever its position in the word (e.g. فـ/ فـ /ف), but this is only applicable to few letters (e.g. $₫$ / $/$ \& ) . Fiset and collaborators (Fiset, Blais, Éthier-Majcher, Arguin, Bub, \& Gosselin, 2008; Fiset et al., 2009) emphasized the significance of horizontals in the perception of Roman letters. However, for Arabic letters most of the horizontal segments occur in the ligatures between letters, and do not, therefore, play an important role in distinguishing between letters. Letter recognition involves a highly constrained visual pattern recognition system: constructing and identifying an abstract concept of a letter or the abstract letter identity from basic visual features (Grainger \& Jacobs, 1996; Grainger, Rey, \& Dufau, 2008) where visual features are mapped onto letter representations (Carreiras, Perea, Gil-López, Abu Mallouh, \& Salillas, 2013).

It is interesting to note that decoding performance in the post-intervention period was better performed in pseudo-words than words. A similar finding was reported in Bara, Gentaz \& Colé (2007), who found that pseudo-word decoding improved more after visual and haptic exploration of letters than visual exploration of letters. This may be explained by the fact that at the end of the program, participants began developing an alphabetic strategy in reading (Bruck, 1990). During the alphabetic phase in reading development (Frith, 1986), the child is able to use correspondences between individual graphemes and phonemes. Words are sequentially decoded grapheme by grapheme. The child can pronounce both unfamiliar words and non-words but will not necessarily generate the correct pronunciation. The use of an alphabetic strategy may be enough for competent reading to acquire basic literacy in Arabic (Azzam, 1993). A similar pattern was reported in other transparent orthographies (Wimmer \& Hummer, 1990). In transparent orthographies like Arabic, it is generally thought that learning to read initially emphasizes alphabetic analysis (Seymour, Aro, \& Erskine, 2003). After two years of reading, such subjects are better at phoneme manipulation and reading non-words than readers of an opaque orthography. 
Our results also reveal that in the post-intervention period, spelling performance measured by sentence dictation increased in the experimental group, indicating that learning to write letters with a multimodal approach (i.e. hand movement in the space, forming letters using clay) increase the participant's experience in writing letters which may improve learning of letter shapes (e.g., James, 2010, Li \& James, 2016; Longcamp et al., 2006; Longcamp et al., 2010; Longcamp et al., 2005). The increase in the perceptual representation of letters in turn may give support to learning to write adequately letters and words by reactivating visual patterns from memory, which recruits the appropriate neural circuit to translate visual patterns to reproduce an approximation of the shape via the motor system (writing). This effect can be interpreted in light of the embodied theory of learning (Glenberg, Witt \& Metcalfe, 2013) as a strong relationship between visual and motor systems in reading and writing (James \& Gauthier, 2006; Longcamp et al., 2003). Based on this theory, visual motor memory ability should affect written language recognition (decoding abilities), as well as influencing written language production. It is likely that the gesture reinforces the visual representation of letters and may favor encoding and recall. This proposal is supported by evidence showing that the motor processes associated with writing reinforce a child's ability to recognize alphabetical symbols (Tan, Spinks, Eden, Perfetti, Siok. 2005). Thus, more practice and procedural recall of letter/word forms (motor representations of symbols) while writing could aid visual recognition while reading (Longcamp et al., 2008). Another factor to consider is that spelling and writing in Arabic in basically consonantal, so that letters represent only consonants while vowels (diacritic signs) can be omitted, which may facilitate the reproduction of learned letters.

Performances on Block Construction and Design Copying subtests also improved at posttest assessment for children receiving the remedial program, whereas pre- and post-test scores did not differ for the control group, indicating a substantial improvement in the visual construction performance may be linked to the visuo-motor activities included in the program. Engagement in visuo-motor activities during program implementation may provide participants 
with opportunities to practice motor integration of visually presented letters and reproducing them by different means. These findings are consistent with the notion that practice with such materials develops visuo-motor integration and coordination.

In summary, this pilot study shows the effectiveness of a visuo-motor based intervention that involved hand reproduction of letter shapes in improving letter knowledge and production which had an impact on the quality of decoding word and pseudo-words and spelling abilities in children with reading and spelling disorders (dyslexia and dysorthography). From a clinical perspective, the results may have important implications, because they show that literacy develops at least partly by interacting with visuo-motor skills. In practice, these results suggest that it would be useful to assess visuo-motor integration skills for screening pre-schoolers in regard to their academic aptitudes. Visuo-motor training facilitates the acquisition of the alphabetic principle in children with low levels of literacy and may also affect typical readers.

\section{References}

Abu-rabia, S. \& Taha, H. (2004) Reading and spelling error analysis of native. Reading and Writing, 17, 651. https://doi.org/10.1007/s11145-004-2657-x

Abu-Rabia, Salim., Sammour R (2013). Spelling Errors' Analysis of Regular and Dyslexic Bilingual Arabic-English Students. Open Journal of Modern Linguistics.3, 1, 58-68 American Psychiatric Association. (2000). Diagnostic and statistical manual of mental disorders (4th ed., text rev.). Washington, DC: Author.

American Psychiatric Association. (2013). Diagnostic and statistical manual of mental disorders (5th ed.). Washington, DC: Author.

Angelelli, P., Judica, A., Spinelli, D., Zoccolotti, P., \& Luzzatti, C. (2004). Characteristics of writing disorders in Italian dyslexic children. Cognitive Behavioural Neurology, 17, 1831. doi:10.1097/00146965-200403000-00003

Azzam, R. (1993). The nature of Arabic reading and spelling errors of young children. Reading and Writing, 5, 4, 355-385. doi:10.1007/BF01043112

Bara, F., Bonneton-Botté, N. (2018) Learning Letters With the Whole Body: Visuomotor Versus Visual Teaching in Kindergarten. Percept Mot Skills. 125 (1),190-207. doi: 10.1177/0031512517742284. 21. 
Bara, F., \& Gentaz, E. (2011). Haptics in teaching handwriting: The role of perceptual and visuomotor skills. Human Movement Science, 30, 745-759.10.1016/j.humov.2010.05.015

Bara, F., Gentaz, E., \& Colé, P. (2007). Haptics in learning to read with children coming from low socio-economic status families. British Journal of Developmental Psychology, 25, 643-663.

Bara, F., Gentaz, E., Colé, P., \& Sprenger-Charolles, L. (2004). The visuo-haptic and haptic exploration of letters increases the kindergarten-children's reading acquisition. Cognitive Development, 19, 433-449

Bellocchi S, Muneaux M, Huau A, Lévêque Y, Jover M, Ducrot S. (2017). Exploring the Link between Visual Perception, Visual-Motor Integration, and Reading in Normal Developing and Impaired Children using DTVP-2. Dyslexia, 23(3), 296-315. doi: 10.1002/dys. 1561.

Berninger VW1, Nielsen KH, Abbott RD, Wijsman E, Raskind W. (2008) Writing problems in developmental dyslexia: under-recognized and under-treated. Journal of School Psychology. 46 (1),1-21. doi: 10.1016/j.jsp.2006.11.008.

Bigozzi, L., Christian, T., Pinto, G., Gamannossi, B.A. (2016). Predicting dyslexia in a transparente orthography from grade 1 literacy skills: a prospective Cohort study. Reading and Writing Quarterly, 32 (1), 353-72.

Blachman, B. A., Tangel, D. M., Ball, E. W., Black, R. S., \& McGraw, C. K. (1999). Developing phonological awareness and word recognition skills: A two-year intervention with lowincome, inner-city children. Reading and Writing, 11, 239-273.

Brady, S. A., \& Shankweiler, D. P. (Eds.). (1991). Phonological processes in literacy: A tribute to Isabelle Y. Liberman. Hillsdale, NJ, US: Lawrence Erlbaum Associates, Inc.

Bruck, M. (1990). Word recognition skills of adults with childhood diagnoses of dyslexia. Developmental Psychology, 26, 439-454

Campbell, M. L. \& Helf, S. \& Cooke, N. L. (2008). Effects of Adding Multisensory Components to a Supplemental Reading Program on the Decoding Skills of Treatment Resisters. Education and Treatment of Children 31(3), 267-295.

Carreiras M., Perea M., Gil-López C., Abu Mallouh R., Salillas E. (2013). Neural correlates of visual vs. abstract letter processing in Roman and Arabic scripts. Journal of Cognitive Neuroscience. 25, 1975-1985. 10.1162/jocn_a_00438

Castles, A. \& Coltheart, M. (1993).Varieties of developmental dyslexia, Cognition, 47, 149-180. de Jong P.F., Messbauer, V.C. (2011) Orthographic Context and the Acquisition of Orthographic Knowledge in Normal and Dyslexic Readers. Dyslexia, 17(2), 107-22 
doi: $10.1002 /$ dys. 427

Dufor, O. \& Rapp, B. (2013). Letter representations in writing: an fMRI adaptation approach.

Frontiers in Cognitive Science, doi: 10.3389/fpsyg.2013.0078

Eden, G. F., \& Moats, L. (2002). the Role of Neuroscience in the Remediation of Students With Dyslexia. Nature Neuroscience, 5, 1080- 1085.

Egan J.,\& Tainturier M. (2011). Inflectional spelling deficits in developmental dyslexia. Cortex, 47, 1179-1196. 10.1016/j.cortex.2011.05.013

Ehri, L. (2005). Learning to read words: Theory, findings, and issues. Scientific Studies of Reading, 9, 167-188.

Ehri, L. C. (2000). Learning to read and learning to spell Two sides of a coin. Topics in Language Disorder, 20, 19-36. doi10.1097/00011363-200020030-00005.

Elbeheri, G. (2004). Developmental dyslexia in Arabic: Devising a diagnostic tool can enrich our understanding of the manifestation of dyslexia amongst monolingual Arabic children. Doctoral thesis, Durham University.

Fiset, D., Blais, C., Arguin, M., Tadros, K., Éthier-Majcher, C., Bub, D., \& Gosselin F. (2009). The spatio-temporal dynamics of visual letter recognition. Cognitive Neuropsychology, 26 (1), 23-35.

Fiset, D., Blais, C., Éthier-Majcher, C., Arguin, M., Bub, D., Gosselin, F. (2008). Features for uppercase and lowercase letter identification. Psychological Science, 19 (11),1161-1168.

Friedmann, N., \& Haddad-Hanna, M. (2012). Letter position dyslexia in Arabic: from form to position. Behavioural Neurology, 25 (3),193-203. doi: 10.3233/BEN-2012-119004

Frith, U. (1986). A developmental framework for developmental dyslexia. Annals of Dyslexia, 36; 69-81.

Gentaz, E., Bara, F., Palluel-Germain, R., Pinet, L., \& Hillairet de Boisferon, A. (2009). Apports de la modalité haptique manuelle dans les premiers apprentissages scolaires [Contributions of manual haptic modality in early school learning]. Cognito-Cahiers Romans de Sciences Cognitives, 3(3), 1-38.

Gentaz, E., Colé, P., \& Bara, F. (2003). Evaluation d'entraînements multisensoriels de préparation à la lecture chez les jeunes enfants de grande section maternelle: Etude sur la contribution du système haptique manuel. Année Psychologique, 104, 561-584

Giese, M.A., \& Rizzolatti, G. (2015). Neural and Computational Mechanisms of Action Processing: Interaction between Visual and Motor Representations. Neuron, 88 (1),16780. doi: 10.1016/j.neuron.2015.09.040. 
Glenberg, A. M., Witt, J. K., and Metcalfe, J. (2013). From the revolution to embodiment: 25 years of cognitive psychology. Perspectives on Psychological Science. 8, 573-585

Goldstand, S., Koslowe, K.C., \& Parush, S. (2005). Vision, visual-information processing, and academic performance among seventh-grade school children: a more significant relationship than we thought? American Journal of Occupational Therapy, 59(4), 377-89.

Grainger, J. \& Jacobs, A.M. (1996). Orthographic processing in visual word recognition: A multiple read-out model. Psychological Review, 103(3), 518-565.

Grainger, J., Rey, A., \& Dufau, S. (2008). Letter perception: From pixels to Pandemonium. Trends in Cognitive Sciences, 12, 381-387.

Hall, A.H., Simpson, A., Guo, Y., \& Wang, S. (2015). Examining the effects of preschool writing instruction on emergent literacy skills: A systematic review of the literature. Literacy Research and Instruction, 54 (2), 115-134

Hammill, D. D. (2004). What we know about correlates of reading. Exceptional Students, 70,453-469

Hulme, C., \& Snowling, M. J. (2014). The interface between spoken and written language: developmental disorders. Phil. Trans. R. Soc. B 369: 20120395. doi 10.1098/rstb.2012.0395.

Ibrahim, R., Eviatar, Z., \& Aharon-Peretz, J. (2002). The characteristics of Arabic orthography slow its processing. Neuropsychology, 16, 322- 326. doi:10.1037/0894-4105.16.3.322

INSERM, Collective Expert Reports (2007). Dyslexia Dysorthography Dyscalculia: Review of the scientific data. Institut national de la santé et de la recherche médicale. Available from: https://www.ncbi.nlm.nih.gov/books/NBK10787/

James, K.H. (2010) Sensori-motor experience leads to changes in visual processing in the developing brain, Developmental Science, 13(2) 279-288.

James, K. H., \& Engelhardt, L. (2012). The effects of handwriting experience on functional brain development in pre-literate children. Trends in Neuroscience and Education, 1, 32- 42. http://dx.doi.org/10.1016/j.tine .2012.08.001

James, K. H., \& Gauthier, I. (2006). Letter processing automatically recruits a sensory-motor brain network. Neuropsychologia, 44 (14), 2937-2949.

Kersey, A. J., \& James, K. H. (2013). Brian activation patterns resulting from learning letter forms through active self-production and passive observation in young children. Frontiers in Cognitive Science, 4, 1-15. 
Knight, D., \& Rizzuto, T. (1993). Relations for children in grades 2, 3, and 4 between balance skills and academic achievement. Perception and. Motor Skills, 76, 1296-1298. doi: 10.2466/pms.1993.76.3c.1296

Korkman, M., Kirk, U., \& Kemp, S. (1998).NEPSY: A developmental neuropsychological assessment. San Antonio,TX: The Psychological Corporation.

Korkman, M., Kirk, U., \& Kemp, S. (2007). NEPSY-Second Edition (NEPSY-II). San Antonio, TX: Harcourt Assessment. Journal of Psychoeducational Assessment, 28, 2, 175-182

Labat, H., Ecalle, J., \& Magnan, A. (2010). Effet d'entrainements bimodaux a` la connaissance des lettres. Etude transversale chez des enfants de trois a cinq ans. [Effect of dual-mode training in letter knowledge: A cross-sectional study with 3- and 5-year-old children]. Psychologie Française, 55, 113-127

Landerl, K. Wimmer, H. (2000). Deficits in phoneme segmentation are not the core problem of dyslexia: evidence from German and English children. Applied Psycholinguistics, 21, 243-262

Layes, S., Lalonde, R., Mecheri, S., \& Rebaï, M. (2015). Phonological and cognitive reading related skills as predictors of word reading and reading comprehension among Arabic dyslexic children. Psychology, 6, 20-38.

Layes,S., Lalonde, R., Rebaï, M. (2014). Reading speed and phonological awareness deficits among Arabic-speaking children with dyslexia. Dyslexia, 21 (1), 80-95.

Li, J.X., James K.H. (2016). Handwriting Generates Variable Visual Output to Facilitate Symbol Learning. Journal of Experimental Psychology, 145, 3, 298 -313

Longcamp, M., Anton, J. L., Roth, M., \& Velay, J. L. (2005). Premotor activations in response to visually presented single letters depend on the hand used to write: a study on left-handers. Neuropsychologia, 43(12):1801-1809.

Longcamp, M., Anton, J. L., Roth, M., \& Velay, J. L. (2003). Visual presentation of single letters activates a premotor area involved in writing. NeuroImage, 19, 1492-1500.

Longcamp, M., Boucard, C., Gilhodes, J. C., \& Velay, J. L. (2006). Remembering the orientation of newly learned characters depends on the associated writing knowledge: A comparison between handwriting and typing. Human Movement Science, 25, 646 - 656. Doi.org/10 .1016/j.humov.2006.07.007

Longcamp, M., Boucard, C., Gilhodes, J.C., Anton, J.L., Roth, M., Nazarian, B. and Velay, J.L. (2008) Learning through Hand- or Typewriting Influences Visual Recognition of New Graphic Shapes: Behavioral and Functional Imaging Evidence. Journal of Cognitive Neuroscience, 20, 802-815. http://dx.doi.org/10.1162/jocn.2008.20504 
Longcamp, M., Lagarrigue, A., \& Velay, J.-L. (2010). Contribution de la motricité graphique à la reconnaissance visuelle des lettres [Contribution of writing movements to visual recognition of letters]. Psychologie Française, 55(2), 181-194.

Longcamp, M., Zerbato-Poudou, M., \& Velay, J. L. (2005). The influence of writing practice on letter recognition in preschool children: A comparison between handwriting and typing. Acta Psychologia, 119, 67-79

Lust, C. and Donica, D. (2011) Effectiveness of a Handwriting Readiness Program in Head Start: A Two-Group Controlled Trial. Research Scholars Initiative. 65 (5): 560-568.

Lyon, G. R., Shaywitz, S. E., \& Shaywitz, B. A. (2003). A definition of dyslexia. Annals of Dyslexia, 53 1-14. 10.1007/s11881-003-0001-9

Longcamp, M., Richards, T.L., Velay, J.L., \& Berninger, V.W. (2016). Neuroanatomy of Handwriting and Related Reading and Writing Skills in Adults and Children with and without Learning Disabilities: French-American Connections. Pratiques, 3175, 171-172.

Moats, L., \& Farrell, M. (2002). Multisensory instruction. In J. Birsh (Ed.), Multisensory Teaching of Basic Language Skills (pp. 1-18). Baltimore: Brookes Publishing Co.

Moll, K., Kunze, S., Neuhoff, N., Bruder, J. \& Schulte-Körne, G. (2014). Specific learning disorder: Prevalence and sex differences. PloS One, 9(7) e103537. DOI:10.1371/journal.pone.0103537.

Neumann, M. M., Hood, M., \& Ford, R. M. (2013). Using environmental print to enhance emergent literacy and print motivation. Reading and Writing, 26(5), 771-793. https://doi.org/10.1007/s11145-012-9390-7.

Suárez-Coalla, P., Villanueva, N., González-Pumariega, S., \& González-Nosti, M.(2016). Spelling difficulties in Spanish-speaking children with dyslexia / Dificultades de escritura en niños españoles con dyslexia. Infancia y Aprendizaje: Journal for the Study of Education and Development, 39, 2, 291-311doi:10.1080/02103702.2015.1132979

Pennington, B.F., \& Lefly, D. L. (2001). Early reading development in children at family risk for dyslexia. Child Development, 72, 816-833.

Perfetti, C. A., \& Sandak, R. (2000). Reading optimally builds on spoken language: Implications for deaf readers. Journal of Deaf Studies and Deaf Education, 5, 32-50. doi:10.1093/deafed/5.1.32

Pierangelo,R., \& Giuliani,G. (2007). The Educator's Diagnostic Manual of Disabilities and Disorders (EDM). San Francisco, CA: Jossey-Bass. 
Good, R.H., Baker, S.K., \& Peyton, J.A. (2008). Making Sense of Nonsense Word Fluency: Determining Adequate Progress in Early First-Grade Reading, Reading \& Writing Quarterly, 25 (1), 33-56, DOI: 10.1080/10573560802491224

Sayeski, K. L (2011). Effective Spelling Instruction for Students with Learning Disabilities. Intervention in School and Clinic, 47(2), 75-81

Schiff, R., \& Levie, R. (2017). Spelling and morphology in dyslexia: a developmental study across the school years. Dyslexia, 23(2):1-21.

Seymour, P. H. K., Aro, M., \& Erskine, J. (2003). Foundation literacy acquisition in European orthographies. British Journal of Psychology, 94, 143-174.

Son, S.H., \& Meisels, S.J. (2006). The relationship of young children's motor skills to later reading and math achievement. Merrill-Palmer Quarterly, 52,755-778.

Tan, L. H., Spinks, J. A., Eden, G. F., Perfetti, C. A., \& Siok, W. T. (2005). Reading depends on writing, in Chinese. Proceedings of the National Academy of Sciences, 102, 8781-8785. doi.org/10.1073/pnas.0503523102

Tops, W., Callens, M., \& Brysbaert, M. (2012). Spelling in Adolescents with Dyslexia: Errors and Modes of Assessment . Journal of Learning Disabilities, 47 (4), 295-306

Tops, W., Callens, M., Bijn, E., \& Brysbaert, M. (2014). Spelling in Dutch adolescents with dyslexia: Errors and modes of assessment. Journal of Learning Disabilities, 47, 295-306

Treiman, R., Tincoff, R., Rodriguez, K., Mouzaki, A., \& Francis, D.J. (1998). The foundations of literacy: Learning the sounds of letters. Child Development, 69, 1524-1540

Tunmer, W. E., \& Nesdale, A. R. (1985). Phonemic segmentation skill and beginning reading. Journal of Educational Psychology, 77(4), 417-427

Vaessen A, Blomert L. (2013). The cognitive linkage and divergence of spelling and reading development. Scientific Studies of Reading, 17 (2):89-107.

Vinter, A., \& Chartrel, E. (2010). Effects of Different Types of Learning on Handwriting Movements in Young Children. Learning and Instruction, 20, 476-486. https://doi.org/10.1016/j.learninstruc.2009.07.001

Weiser, B., \& Mathes, P. (2011). Using Encoding Instruction to Improve the Reading and Spelling Performances of Elementary Students at Risk for Literacy Difficulties. A BestEvidence Synthesis. Review of Educational Research. https://doi.org/10.3102/0034654310396719

Wiley, R.W., Wilson, C., \& Rapp, B. (2016). The effects of alphabet and expertise on letter perception through active self-production and passive observation in young children, Frontiers in Psychology, 4, 567. 
Wimmer, H., \& Hummer, P. (1990). How German-speaking first graders read and spell: Doubts on the importance of the logographic stage. Applied Psycholinguistics, 11, 349-368

Zemlock, D., Vinci-Booher, S. \& James, K.H. (2017). Visual-motor symbol production facilitates letter recognition in young children. Reading and Writing, 31, 1255. https://doi.org/10.1007/s11145-018-9831-z

Table 1. Comparison between the two groups in the pre-intervention measures

\begin{tabular}{|c|c|c|c|}
\hline Measures & Group & $\begin{array}{l}\text { Pre-intervention } \\
\text { Mean } \pm \text { SD }\end{array}$ & t-test value, Sig \\
\hline Age & $\begin{array}{l}\text { Experiment } \\
\text { Control }\end{array}$ & $\begin{array}{l}125.50 \pm 3.24 \\
124.10 \pm 3.31\end{array}$ & $\mathrm{t}=.95, \mathrm{p}>.05$ \\
\hline Raven & $\begin{array}{l}\text { Experiment } \\
\text { Control }\end{array}$ & $\begin{array}{l}22.40 \pm 3.89 \\
21.80 \pm 2.57\end{array}$ & $\mathrm{t}=.40, \mathrm{p}>.05$ \\
\hline Frequent word & $\begin{array}{l}\text { Experiment } \\
\text { Control }\end{array}$ & $\begin{array}{l}13.70 \pm 5.05 \\
13.10 \pm 4.33\end{array}$ & $\mathrm{t}=.28, \mathrm{p}>.05$ \\
\hline Infrequent word & $\begin{array}{l}\text { Experiment } \\
\text { Control }\end{array}$ & $\begin{array}{l}3.80 \pm 3.22 \\
3.70 \pm 2.16\end{array}$ & $\mathrm{t}=.08, \mathrm{p}>.05$ \\
\hline Total word & $\begin{array}{l}\text { Experiment } \\
\text { Control }\end{array}$ & $\begin{array}{l}17.50 \pm 7.38 \\
16.80 \pm 5.37\end{array}$ & $\mathrm{t}=.24, \mathrm{p}>.05$ \\
\hline Pseudo word & $\begin{array}{l}\text { Experiment } \\
\text { Control }\end{array}$ & $\begin{array}{l}0.80 \pm 1.03 \\
2.30 \pm 2.31\end{array}$ & $\mathrm{t}=-1.78, \mathrm{p}>.05$ \\
\hline $\begin{array}{l}\text { Sentence dictation } \\
\text { (spelling) }\end{array}$ & $\begin{array}{l}\text { Experiment } \\
\text { Control }\end{array}$ & $\begin{array}{l}2.70 \pm 1.56 \\
2.60 \pm 1.43\end{array}$ & $\mathrm{t}=.15, \mathrm{p}>.05$ \\
\hline Design Copying & $\begin{array}{l}\text { Experiment } \\
\text { Control }\end{array}$ & $\begin{array}{l}10.90 \pm 3.28 \\
15.10 \pm 4.81\end{array}$ & $\mathrm{t}=-2.20, \mathrm{p}<.05$ \\
\hline $\begin{array}{l}\text { Block } \\
\text { Construction }\end{array}$ & $\begin{array}{l}\text { Experiment } \\
\text { Control }\end{array}$ & $\begin{array}{l}5.00 \pm 1.94 \\
6.80 \pm 5.05\end{array}$ & $\mathrm{t}=-1.05, \mathrm{p}>.05$ \\
\hline
\end{tabular}




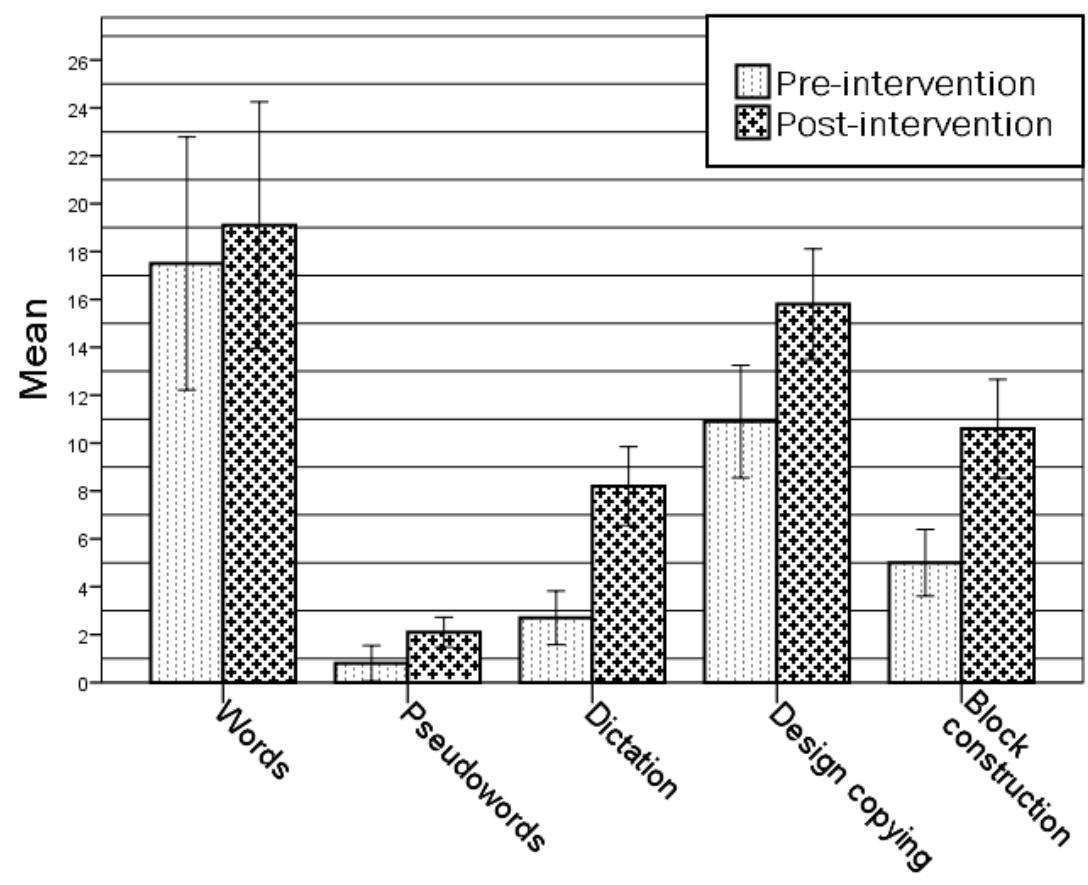

Figure 1. Comparison between pre and post intervention measures in the experimental group 


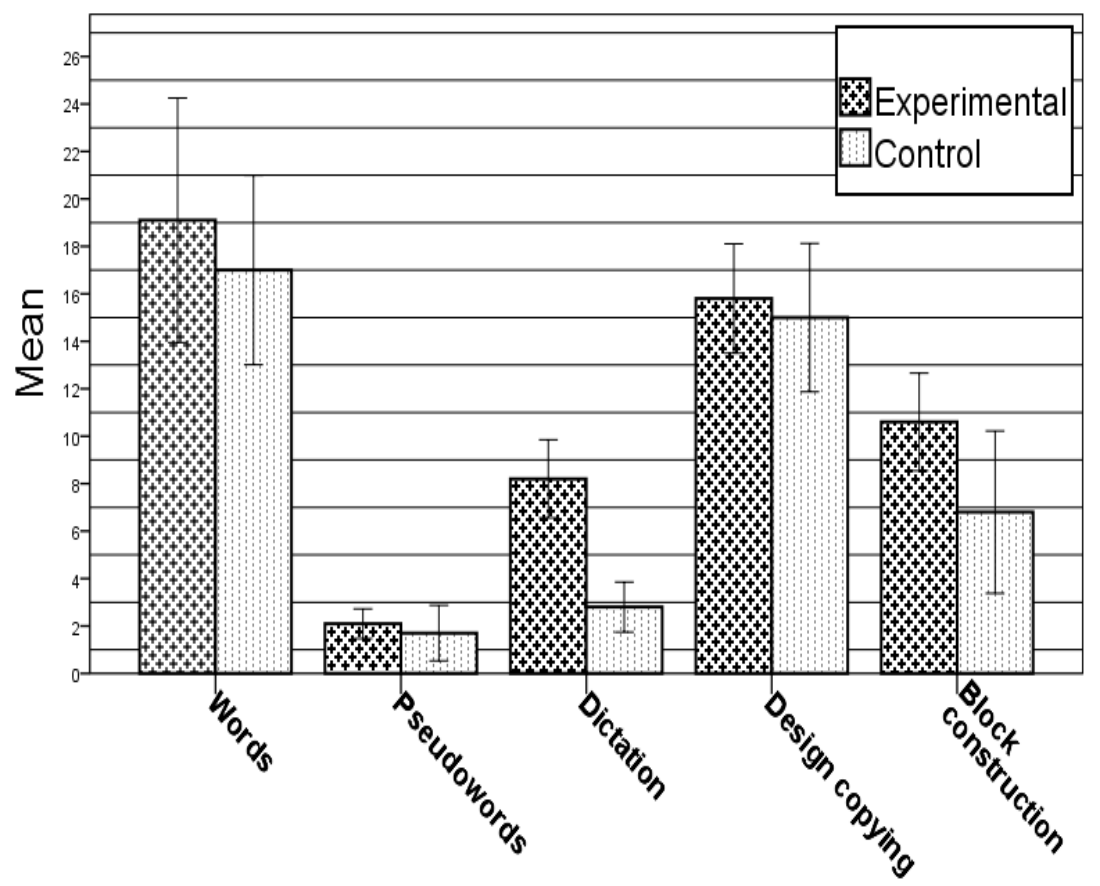

Figure 2. Comparison between the two groups in the post-intervention measures 